\title{
Solution Properties and Structure of Brain Proteolipids
}

\author{
ROBERT ZAND, Biophysics Research Division, Institute of Science and \\ Technology, The University of Michigan, Ann Arbor, Michigan 4810 '
}

\begin{abstract}
Synopsis
Bovine white matter proteolipids have been studied by several physical methods and have been found to exist as micelles in $2: 1(\mathrm{v} / \mathrm{v})$ chloroform-methanol solution. The data would indicate the existence of a critical micelle concentration at $0.017-0.022$ $\mathrm{g} / 100 \mathrm{ml}$. The curve appears linear in the range $0.017-0.2 \mathrm{~g} / 100 \mathrm{ml}$, but from the data at higher concentrations it would appear that a change in slope is occurring in the region $0.2-0.3 \mathrm{~g} / 100 \mathrm{ml}$. Light-scattering measurements on $2: 1(\mathrm{v} / \mathrm{v})$ chloroformmethanol solutions containing more than $0.2 \mathrm{~g} / 100 \mathrm{ml}$ of proteolipid yielded a weightaverage aggregate weight of $2.9 \times 10^{6}$ and a radius of gyration of $645 \AA$. The intrinsic viscosity of the solutions was $0.32 \mathrm{dl} / \mathrm{g}$ and the Huggins constant was 1.085 . Lightscattering measurements in $88.5 \%$ formic acid- $0.5 \mathrm{M}$ sodium formate yielded a weightaverage aggregate weight of $7.1 \times 10^{6}$ and a radius of gyration of $241 \AA$. The intrinsic viscosity observed for this solvent system is $0.14 \mathrm{dl} / \mathrm{g}$ and the Huggins constant is 1.005 . Osmotic pressure measurements in $2: 1(\mathrm{v} / \mathrm{v})$ chloroform-methanol containing less than $0.2 \mathrm{~g} / 100 \mathrm{ml}$ of proteolipid yielded a number-average aggregate weight of $7.2 \times 10^{4}$ Ultracentrifugal analysis in 1.5:1 (v/v) methylene chloride-methanol showed two broad peaks with $s$ values of $s_{1.5 \%}=25.05 \mathrm{~S}, s_{2 \%}=19.79 \mathrm{~S}$ for the minor peak and $s_{1.5 \%, 2 \%}=1.86 \mathrm{~S}$ for the major peak. Optical rotatory dispersion studies revealed large changes in $b_{0}$ with change in solvent and proteolipid concentration. The present data suggest that the mode of attachment of protein to lipid is primarily of a noncovalent type. The results of this investigation also suggest that the proteolipid micelle above $0.2 \mathrm{~g} / 100 \mathrm{ml}$ is cylindrical (prolate ellipsoid) in 2:1 $(\mathrm{v} / \mathrm{v})$ chloroform-methanol and approaches a more spherical shape in $88.5 \%$ formic acid. A structure for the proteolipid micellar complex above concentrations of $0.2 \mathrm{~g} / 100 \mathrm{ml}$ is proposed.
\end{abstract}

\section{INTRODUCTION}

The isolation and chemical characterization of $2: 1(\mathrm{v} / \mathrm{v})$ chloroformmethanol soluble protein-lipid complexes from bovine brain tissue was first reported in 1951 by Folch and Lees, ${ }^{1}$ and the name proteolipid was suggested in order to distinguish this complex from the water-soluble lipoproteins. The proteolipids derived from brain tissue have since been studied in several laboratories, ${ }^{2-8}$ the earlier findings have been confirmed, and the proteolipids have been further characterized by chemical methods. All published studies on proteolipids have been primarily concerned with the preparation, determination of composition, and chemical reactions of the complex. These studies have demonstrated the ability of proteolipid 
to undergo fragmentation into denatured protein and $2: 1(\mathrm{v} / \mathrm{v})$ chloroform-methanol-soluble lipid. ${ }^{9}$ Techniques for removing the lipid moiety, while maintaining the solubility of the protein component, have also been reported. ${ }^{10,11}$ The procedure devised by Matsumoto ${ }^{10}$ yields a product containing up to $5 \%$ polyphosphoinositide lipid. The procedure reported by Tenenbaum ${ }^{11}$ yields a product containing $0 \%$ lipid. The present investigation has utilized physical-chemical techniques to characterize bovine white matter proteolipids in $2: 1(\mathrm{v} / \mathrm{v})$ chloroform-methanol and in $88.5 \%$ formic acid solvents. Some studies on the delipidized protein have also been made. The present work, in conjunction with relevant information from the literature, permits a new theory of the nature and structure of proteolipids in solutions.

\section{EXPERIMENTAL}

Proteolipids were prepared from bovine white matter by the emulsion centrifugation method of Folch et al. ${ }^{12}$ Water-soluble proteolipid protein was prepared by the method of Tenenbaum and Folch-Pi. ${ }^{11}$

Chloroform, methanol, and ethanol were reagent-grade chemicals and were redistilled before being used. All other chemicals were not further purified except in special instances detailed elsewhere.

Light-scattering measurements were made with a Brice-Phoenix lightscattering instrument, Model 1000 (Phoenix Precision Instrument Co., Philadelphia, Pa.). Conical thin wall cells were immersed in benzene contained in a cylindrical cell in order to diminish reflections from the cell surface. Some experiments were performed with a SOFICA model 701 (Hewlett-Packard $\mathrm{F}$ and $\mathrm{M}$ Division, Avondale, Pa.) light-scattering photometer. Cells for this instrument were of the cylindrical thin-wall type and were also immersed in benzene.

Solutions were made dust-free by passing them through an ultrafine sintered glass pressure filter and/or centrifuging in stainless steel tubes at $20,000 \mathrm{rpm}$ for $1 \mathrm{hr}$. Measurements were made at a temperature of $25.0 \pm 1.0^{\circ} \mathrm{C}$.

Refractive index measurements were made with an Abbé model $3 \mathrm{~L}$ Bausch and Lomb refractometer.

Differential refractive index measurements were made with a BricePhoenix model BP-2000-V (Phoenix Precision Instrument Co.) differential refractometer. The instrument was calibrated with $\mathrm{KCl}$ solutions and was maintained at $25.00 \pm 0.01^{\circ} \mathrm{C}$.

Osmotic pressure determinations were made with a Stabin model M-1 Zimm-Meyerson osmometer (J. V. Stabin, Brooklyn, New York). Osmometer membranes were $\mathbf{S}$ and $\mathbf{S}$ brand superdense cellophane (Schleicher and Schuell Co., Keene, New Hampshire) that were conditioned by gradually changing solvent from $50 \%$ methanol to $2: 1(\mathrm{v} / \mathrm{v})$ chloroformmethanol. The osmometer was kept in a constant temperature bath at $25.00 \pm 0.01^{\circ} \mathrm{C}$. 
Viscosity measurements were made in Ubbelohde suspended-level viscometers at $25.00 \pm 0.01^{\circ} \mathrm{C}$. The flow time for $2: 1(\mathrm{v} / \mathrm{v})$ chloroformmethanol solvent was 150.8 sec, and for $88.5 \%$ formic acid solvent the flow time was 397.0 sec. Kinetic energy corrections were not required for solvent flow times of this duration.

Ultracentrifugal runs were made in a Spinco model $\mathrm{E}$ ultracentrifuge at $25^{\circ} \mathrm{C}$ using standard sector-shaped cells and schlieren optics. Temperature was $25^{\circ} \mathrm{C}$ and rotor speed 56,100 . Sedimentation constants were calculated from plots of $\log$ (distance) versus time.

Optical rotatory dispersion measurements were made either with a Rudolph model 200S-340 spectropolarimeter (O. C. Rudolph and Sons, Inc., Fairfield, New Jersey), a Cary model 60 spectropolarimeter (Applied Physics Corp., Monrovia, California), or a Durrum Jasco ORD/UV model 5 spectropolarimeter (Durrum Instrument Co., Palo Alto, California).

Ultraviolet absorption spectra were recorded on a Cary model 15 or a Beckman model DB spectrophotometer.

The $\mathrm{x}$-ray powder and film diagrams were obtained with $\mathrm{CuK} \alpha$ x-rays $(\lambda=1.5418 \AA)$ and a standard cylindrical camera.

All proteolipid concentration determinations in this study are based on dry weight determinations in air at room temperature on the individual sample or, when this was not feasible, as in the case of very dilute solutions, dry weights were determined on a stock solution and concentrations were based on quantitative dilution of this stock solution.

\section{RESULTS}

The proteolipids utilized for these experiments were characterized by analysis. Results are shown in Table I. Analytical data for the watersoluble protein from this proteolipid are also shown.

TABLE I

\begin{tabular}{|c|c|c|}
\hline & Found & Reported \\
\hline \multicolumn{3}{|l|}{ Proteolipid } \\
\hline$E_{1}^{1} \%(\lambda=280)$ & 11.8 & $8.8-11.2^{\mathrm{a}}$ \\
\hline Phosphorus, $\%$ & 1.03 & $0.97-1.22^{\mathrm{a}}$ \\
\hline Galactose, $\%$ & 0.654 & $0.59-1.96^{\mathrm{a}}$ \\
\hline Cholesterol, \% & 0.0 & $0-1^{\mathrm{a}}$ \\
\hline$\alpha-\mathrm{NH}_{2}$-acid nitrogen, $\%$ & $8.07 \%$ & $6.05-7.45^{\mathrm{a}}$ \\
\hline \multicolumn{3}{|l|}{ Water-soluble protein } \\
\hline$E_{1}^{1} \stackrel{\%}{\mathrm{~cm}}(\lambda=280)$ & 19.0 & $16.9-22.8^{b}$ \\
\hline Phosphorus, $\%$ & 0.015 & $0.04-0.09^{b}$ \\
\hline Cholesterol, \% & 0.0 & $0.0^{\mathrm{b}}$ \\
\hline $\begin{array}{c}\text { Protein content } \\
\text { (duplicate determination), } \%\end{array}$ & 100,105 & $95-97^{b}$ \\
\hline
\end{tabular}

a Data of Folch. ${ }^{13}$

h Data of Tenenbaum and Folch-Pi. ${ }^{11}$ 


\section{Critical Micelle Concentration}

The critical micelle concentration of proteolipids in $2: 1(\mathrm{v} / \mathrm{v})$ chloroform-methanol was determined by light scattering according to the method of Debye. ${ }^{14}$ The data are presented graphically in Figure 1. The two changes in slope indicating the existence of critical micelle concentrations occur at approximately $0.017 \mathrm{~g} / 100 \mathrm{ml}$ and probably somewhere between 0.2 and $0.3 \mathrm{~g} / 100 \mathrm{ml}$. The critical micelle concentration occurring at the higher concentration is also discernible in the viscosity data (Fig. 4) and the osmotic pressure data (Fig. 5) (ca. $0.2 \mathrm{~g} / 100 \mathrm{ml}$ ).

\section{Light Scattering}

The results of a typical light scattering measurement in $2: 1(\mathrm{v} / \mathrm{v})$ chloroform-methanol solvent saturated with $\mathrm{NaCl}\left(\right.$ ca. $2.97 \times 10^{-3} \mathrm{M}$ ) are shown in Figure $2 a$. The treatment of the data according to the method of Zimm, ${ }^{15}$ which consists of plotting $K C / R_{\theta}$ versus $\sin ^{2} \theta / 2+k C$, where

$$
K=2 \pi^{2} n_{0}^{2}(d n / d c)^{2} / N \lambda^{4}
$$

and $R$ is an arbitrary scaling constant, requires modification for a twocomponent solvent system. The term $d n / d c$ must be replaced by a term $d n / d c+A d n / d v_{1}$ where $d n / d c$ applies to the mixed solvent, $v_{1}$ is the volume fraction of solvent 1 in the medium and $A$ is the adsorption constant which is equal to $-d v_{1} / d c$. It is permissible to evaluate the total expression by carrying out an equilibrium dialysis experiment and by placing dialysate in one compartment and dialyzand in the other compartment of the differential refractometer cell. The measured $d n / d c$ is the value for the expression $d n / d c+A d n / d v_{1}{ }^{16}$ For proteolipid in 2:1 (v/v) chloroformmethanol saturated with $\mathrm{NaCl}$ this was equal to 0.1043 for a wavelength of $546 \mathrm{~m} \mu$, and 0.1090 for a wavelength of $436 \mathrm{~m} \mu$. The value of the refractive index $n$ was taken as 1.4045 . It is also possible to determine the value for $A$, which is a measure of the preferential adsorption of molecules of solvent component 1 (in this instance chloroform) and $A$ was found to be equal to $0.32 \mathrm{~g}$ chloroform $/ \mathrm{g}$ proteolipid. For the system formic acid $-0.5 M$ sodium formate this correction is not required, ${ }^{17,18}$ and $d n / d c$ was de-

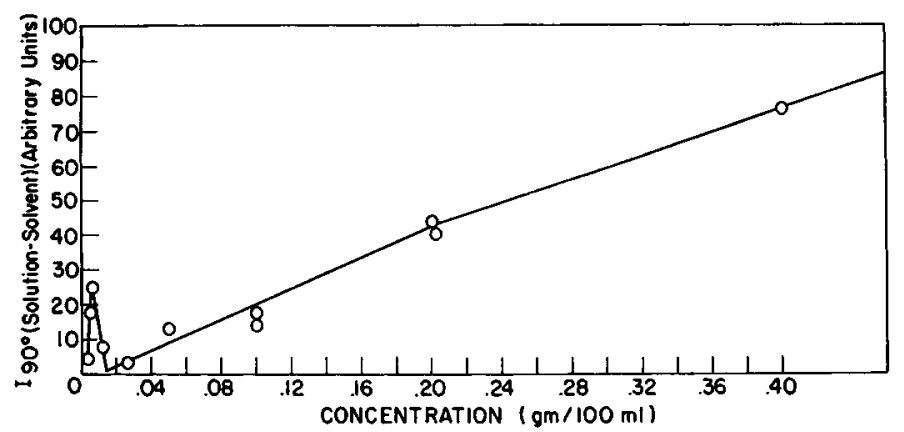

Fig. 1. Critical micelle concentration as determined by light scattering. 

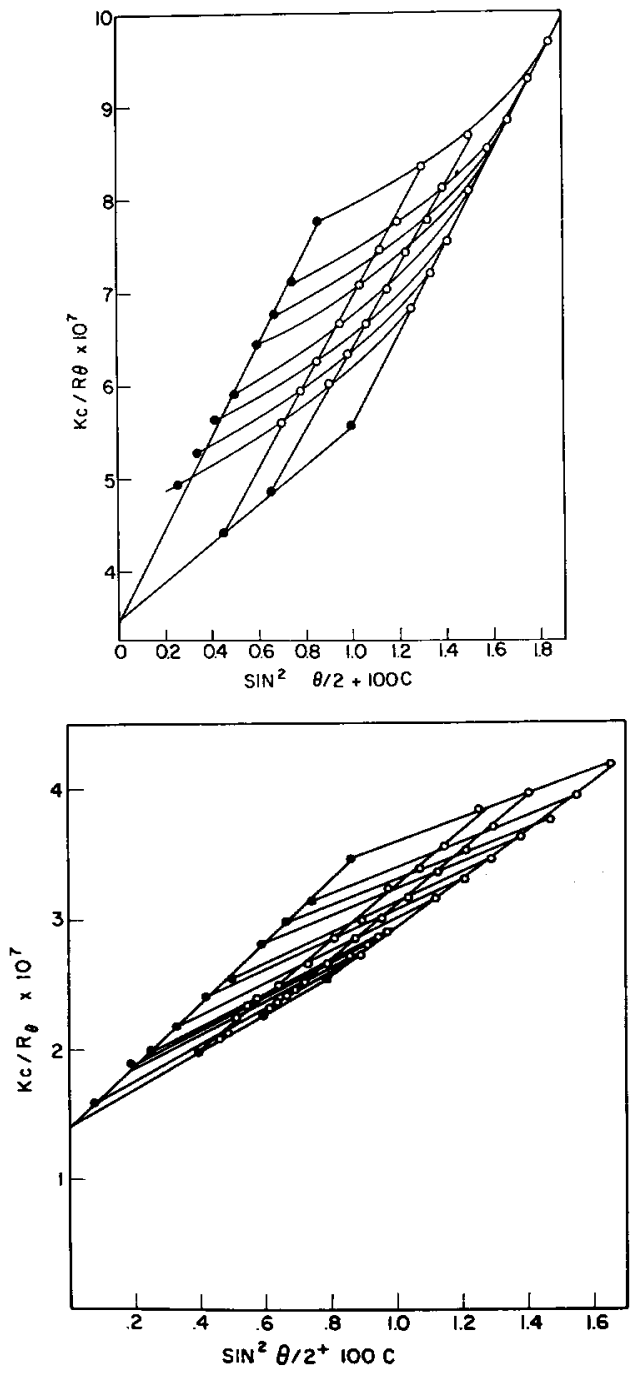

Fig. 2. Zimm plots of light-scattering data: $(a)$ for proteolipids in 2:1 (v/v) chloroformmethanol; $(b)$ for proteolipids in $88.5 \%$ formic acid- $0.5 M$ sodium formate.

termined to be 0.1209 at a wavelength equal to $546 \mathrm{~m} \mu$. The refractive index for this solvent was measured and found to be 1.3700. The results of a typical light scattering measurement in this solvent are shown in Figure $2 b$. In Figure $2 a$ the intersection of the curves for zero angle and zero concentration yields an intercept equal to $3.45 \times 10^{-7}$. The reciprocal of the intercept is the weight-average aggregate weight and was calculated as $2.9 \times 10^{6}$. The radius of gyration was calculated from the relation

$$
R_{\mathrm{G}}=\sqrt{\frac{\text { slope } / \text { intercept }}{16 \pi^{2} / 3 \lambda^{2}}}
$$


The value of $R_{\mathrm{G}}$ determined was $645 \AA$. A similar treatment of the data presented in Figure $2 b$ yielded a weight-average aggregate weight of $7.1 \times$ $10^{6}$ and a radius of gyration equal to $241 \AA$.

\section{Ultracentrifugation}

The schlieren patterns obtained from sedimentation velocity ultracentrifuge runs on solutions of proteolipid in 1.5:1 (v/v) methylene chloride-methanol saturated with sodium chloride showed two peaks. The $2: 1(\mathrm{v} / \mathrm{v})$ chloroform-methanol solvent system was not useful for the ultracentrifuge studies since its density is very near that of the proteolipids. The single solvent systems such as 2,2,2-trichloroethanol were also unsuitable for ultracentrifugal studies because of their high viscosity. In the $1.5: 1(\mathrm{v} / \mathrm{v})$ methylene chloride-methanol solvent the minor peak

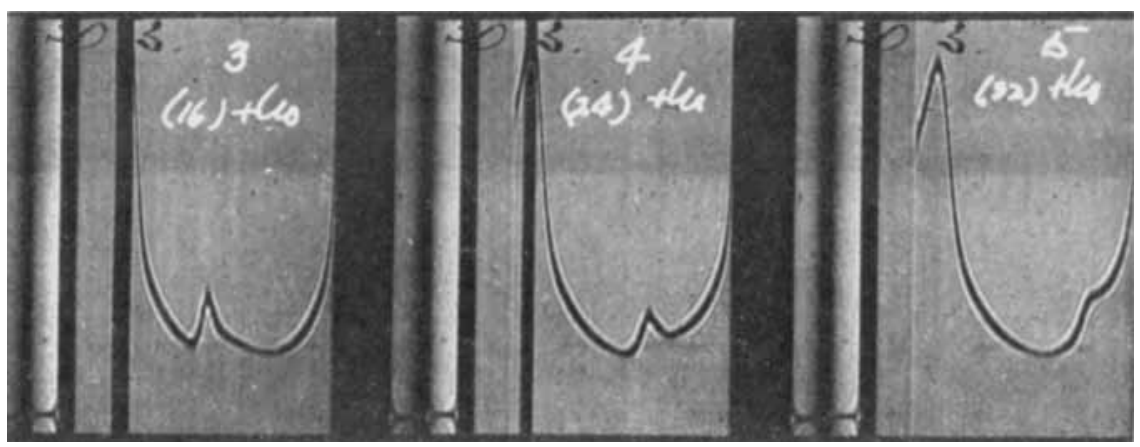

Fig. 3. Sedimentation velocity with the use of schlieren optics on solutions of proteolipids in 1.5:1 (v/v) methylene chloride-methanol containing $2.97 \times 10^{-3} \mathrm{M} \mathrm{NaCl}$; $56,000 \mathrm{rpm}, 25^{\circ} \mathrm{C}$ : pictures (left to right) after $16 \mathrm{~min}, 24 \mathrm{~min}$, and $32 \mathrm{~min}$.

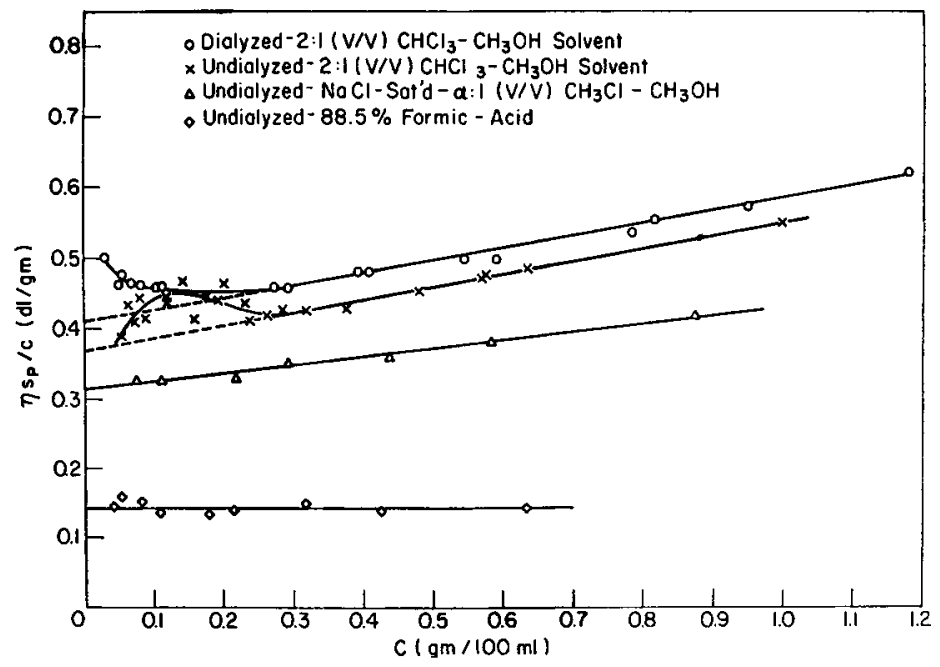

Fig. 4. Viscosity of proteolipids determined under different solvent conditions. 
amounted to $15.5 \%$ of the total concentration and had a sedimentation coefficient of $s_{1.5 \%}=25.05 \mathrm{~S}$ and $s_{2} \%=19.79 \mathrm{~S}$, while the major peak accounted for $84.5 \%$ of the total concentration and had $s_{1.5 \%, 2 \%}=1.86 \mathrm{~S}$. Portions of a typical run are shown in Figure 3.

\section{Viscosity}

The results of viscosity measurements on solutions of proteolipids, in $2: 1$ $(\mathrm{v} / \mathrm{v})$ chloroform-methanol, treated in different ways and on solutions of proteolipids in $88.5 \%$ formic acid are shown in Figure 4 . The reduced specific viscosity is a linear function of concentration above $0.2 \mathrm{~g} / 100 \mathrm{ml}$ for all cases and the data were fitted by the equations: $\eta_{s p} / c=[\eta]+K_{1}[\eta]^{2} c$ and $\eta_{s p} / c=[\eta]+k c$, where $[\eta]$ is the intrinsic viscosity and $K_{1}$ or $k$ is a constant. ${ }^{19,20}$ The intrinsic viscosities and the values of $K_{1}$ and $k$ calculated from the above equations are given in Table II.

TABLE II

Viscosity of Bovine White Matter Proteolipids

\begin{tabular}{lccc}
\hline & $\begin{array}{c}\text { Intrinsic } \\
\text { viscosity } \\
{[\eta], \mathrm{dl} / \mathrm{g}}\end{array}$ & $\begin{array}{c}\text { Huggins' } \\
\text { constant } \\
K_{1}\end{array}$ & $\begin{array}{c}\text { Jirgensons' } \\
\text { constant } \\
k\end{array}$ \\
\hline $\begin{array}{l}\text { Dialyzed, } \\
2: 1 \text { (v/v) chloroform-methanol }\end{array}$ & 0.41 & 1.06 & 0.178 \\
$\begin{array}{l}\text { Undialyzed, } \\
2: 1(\mathrm{v} / \mathrm{v}) \text { chloroform-methanol }\end{array}$ & 0.37 & 1.06 & 0.146 \\
$\begin{array}{l}\text { Undialyzed, } \\
2: 1(\mathrm{v} / \mathrm{v}) \text { chloroform-methanol }\end{array}$ & & & \\
$\begin{array}{l}2.97 \times 10^{-3} M \text { NaCl } \\
88.5 \% \text { Formic acid }\end{array}$ & 0.32 & 1.08 & 0.108 \\
& 0.14 & 1.00 & 0.02 \\
\hline
\end{tabular}

\section{Osmotic Pressure}

Osmotic pressure studies in 2:1 (v/v) chloroform-methanol were complicated by a constant diffusion of material from inside the osmometer so that the initial concentration differed from the final concentration by $11 \%$ even after extensive dialysis of the original stock solution. Because of this diffusion, the final pressure was determined by plotting the observed pressure as a function of time and extrapolating to zero time. The results of these experiments are shown in Figure 5. The number-average aggregate weight, in the concentration range from $0.225-0.090 \mathrm{~g} / 100 \mathrm{ml}$ calculated from these data, was $7.2 \times 10^{4}$.

\section{Spectral Studies}

The ultraviolet absorption maxima and values of $E_{1 \mathrm{~cm}}^{1 \%}$ for the proteolipid in $2: 1(\mathrm{v} / \mathrm{v})$ chloroform-methanol and for the water-soluble proteolipid are presented below. The ultraviolet absorption spectrum of the water-soluble proteolipid protein in $1 \times 10^{-3} \mathrm{~N} \mathrm{HCl}$ is shown in Figure 6 . 


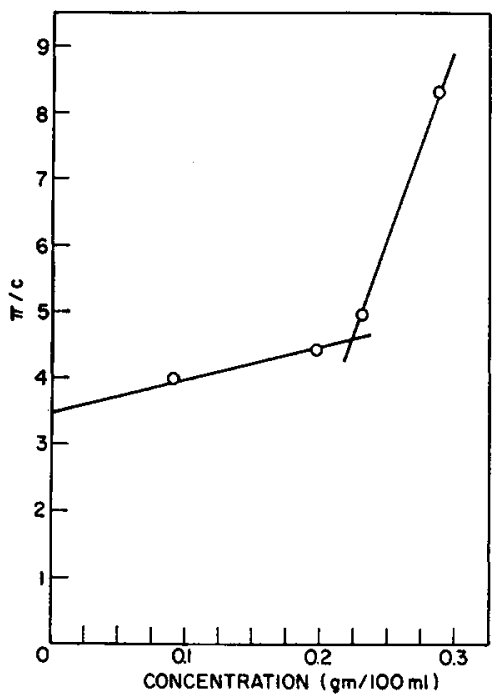

Fig. 5. Osmotic pressure determination of proteolipids in 2:1 (v/v) chloroform-methanol.

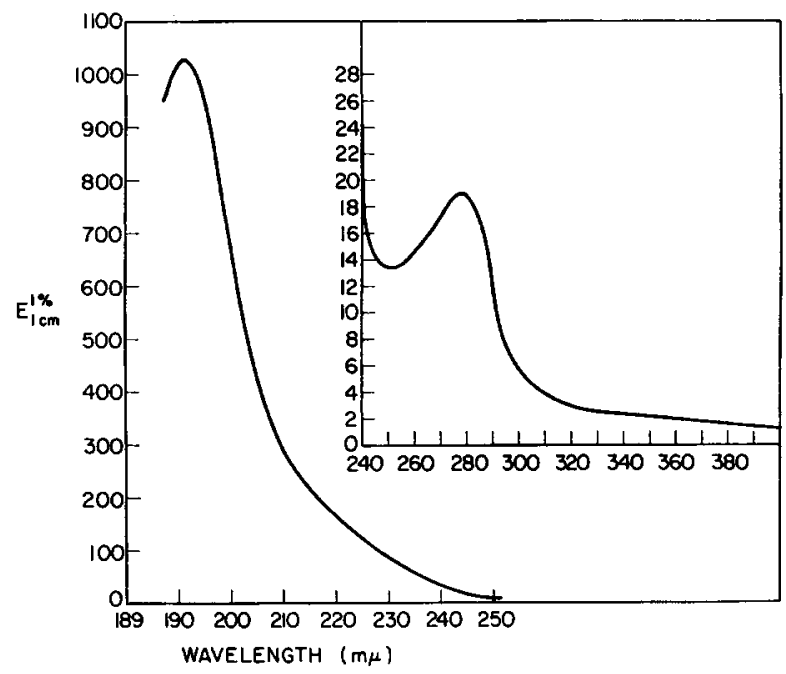

Fig. 6. Ultraviolet spectrum of water-soluble proteolipid protein in $1 \times 10^{-3} \mathrm{~N} \mathrm{HCl}$.

The protein-lipid complex exhibits an $E_{1 \mathrm{~cm}}^{1 \%}=11.8$ at $\lambda_{\max }=280 \mathrm{~m} \mu$ while the protein without any lipid exhibits $E_{1 \mathrm{~cm}}^{1 \%}=19.0$ at $\lambda_{\max }=280 \mathrm{~m} \mu$ and $E_{1 \mathrm{~cm}}^{1 \%}=1035$ at $\lambda_{\mathrm{max}}=192 \mathrm{~m} \mu$.

The optical rotatory dispersion curve for the proteolipid apoprotein in $1.0 \times 10^{-3} \mathrm{~N} \mathrm{HCl}$ solvent is shown in Figure 7. The protein-lipid complex in nonaqueous or aqueous detergent solvent systems could only be studied in the wavelength region where it displayed a plain negative dispersion curve, viz., $600-300 \mathrm{~m} \mu$. These data were fitted by the Moffitt equation ${ }^{21}$ and the values of $b_{0}$ obtained for $\lambda_{0}=212$ are given in Table III. Helix 
TABLE III

Helix Content of Bovine White Matter Proteolipid

\begin{tabular}{|c|c|c|c|}
\hline Solvent for bovine proteolipid & $b_{0}$ & $\begin{array}{l}\text { Estimated fraction } \\
\text { of helix corrected } \\
\text { to } 1 \mathrm{~g} \text { protein }\end{array}$ & $\begin{array}{l}\text { Intensity } \\
\text { of trough } \\
\text { at } 233 \mathrm{~m} \mu\end{array}$ \\
\hline Chloroform-methanol 2:1 & -301.7 & 0.60 & \\
\hline $\begin{array}{l}\text { Cetyltrimethylammonium } \\
\text { bromide, } 1 \% \text { aqueous }\end{array}$ & -200 & 0.40 & \\
\hline Formic acid, $88.5 \%$ & -29.2 & 0.06 & \\
\hline $\begin{array}{l}\text { Water (bovine proteolipid } \\
\text { apoprotein, aqueous) }\end{array}$ & & 0.11 & -3000 \\
\hline
\end{tabular}

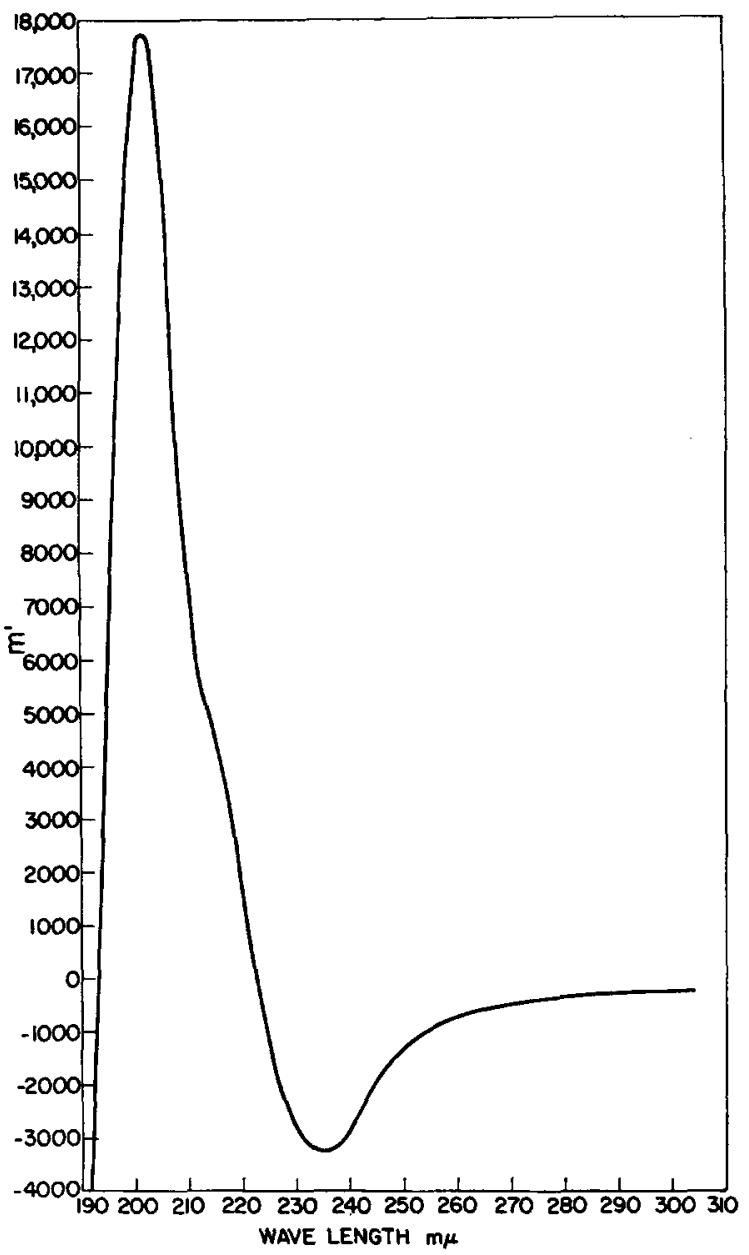

Fig. 7. ORD spectrum of proteolipid in $1 \times 10^{-3} \mathrm{~N} \mathrm{HCl}$. 
contents were estimated by assuming $b_{0}=-630$ for $100 \%$ helix and correcting to $75 \%$ protein content for the proteolipid preparations used.

\section{Solubility and Cation Interactions}

In order to broaden the scope of the studies on the solution behavior of bovine white matter proteolipids a search for a single solvent system was initiated. It was found that the proteolipids were readily soluble in 2,2,2-trichloroethanol, 2,2-dichloroethanol, 2,2-dichloroacetic acid, and 2,3-dichloro-1-propanol.

It has also been observed that proteolipids in $2: 1(\mathrm{v} / \mathrm{v})$ chloroformmethanol solution are precipitated by the following cations $\mathrm{Hg}^{+2}, \mathrm{Cu}^{+2}$, $\mathrm{Al}^{+3}$, and $\mathrm{Tl}^{+4}$. The effect appears to be $\mathrm{pH}$-dependent, but it has not been possible as yet to obtain quantitative data. The proteolipids themselves contain a number of metal ions as revealed by neutron activation analyses. The presence of $\mathrm{Cu}, \mathrm{Mn}$, and $\mathrm{Na}$ as well as $\mathrm{Cl}$ and $\mathrm{Br}$ was demonstrated by this technique.

\section{DISCUSSION}

\section{Definition of Proteolipids}

A high solubility of charge-carrying molecules such as proteins and amino acids in typical lipid solvents having low dielectric constants relative to that of water is not a general characteristic of these substances. It is, however, a phenomenon that is more prevalent than had been previously believed. Thus, conditions for the solubilization of amino acids in petroleum ether ${ }^{22}$ and in chloroform-methanol ${ }^{23}$ have been reported. The requirements for the solubilization of horse heart cytochrome $\mathrm{c}$ in isooctane have also been worked out. ${ }^{24-27}$ Several variations of the original Folch method for preparing bovine brain proteolipids have also been reported, ${ }^{28,29}$ and the isolation of proteolipids from a variety of sources such as plants, ${ }^{30,31}$ beef heart muscle, ${ }^{32}$ and beef heart microsomes ${ }^{33}$ have been reported. It is apparent that a number of proteolipid systems have been isolated, and these proteolipids are themselves capable of being modified, in the course of their preparation or at other times, to give different proteolipid systems. Since a great variety of protein-lipid complexes are known, it is necessary to define the subclass, "proteolipids," by some specific physical-chemical characteristics. The following criteria are suggested as minimum requirements to be satisfied before a protein lipid complex can be termed proteolipid: (1) the protein-lipid complex must contain a minimum of $25 \%$ protein; (2) the lipid moiety must be largely, but need not be exclusively, a phospholipid; (3) the protein-lipid complex must be preferentially soluble in typical lipid solvents; (4) the protein-lipid complex must exhibit at least one clearly demonstrable critical micelle concentration in the lipid solvent.

Since it is now possible to remove the lipid from the protein and retain protein solubility in some solvent, it is suggested that the lipid-free protein 
derived from a proteolipid preparation be designated as proteolipid apoprotein.

\section{Critical Micelle Concentration}

The factor that appears to dominate the solution behavior of proteolipid is its critical micelle concentration. In Figures 1, 4, and 5, the presence of a critical micelle concentration is readily discernible. In Figure 1 the plot of scattering intensity versus concentration is unusual below a concentration of $0.017 \mathrm{~g} / 100 \mathrm{ml}$, since the intensity of scattered light increases rather than decreases. An analogous occurrence has been reported for light-scattering studies of sodium dodecylsulfate micelles in aqueous media. ${ }^{34}$ For this system it was shown that the increase in scattering below the critical micelle concentration could be attributed to some dodecyl alcohol that contaminated the sodium dodecyl sulfate, and the alcohol was no longer solubilized when the micelles were broken up. For proteolipids the increased scattering arises from the protein that is no longer soluble in $2: 1(\mathrm{v} / \mathrm{v})$ chloroform-methanol when the micelles break up. For the proteolipid system used in this study, the major components of the micelle must be phospholipid, protein, and water, although the initial extract of proteolipids must consist of micelles that are more heterogeneous in composition. The presence of two critical micelle regions for solutions of proteolipids in $2: 1(\mathrm{v} / \mathrm{v})$ chloroform-methanol is analogous to the behavior of lecithin in benzene solvent. Egg lecithin in benzene is reported to have a critical micelle concentration at $0.073 \mathrm{~g} / 100 \mathrm{ml}$ and a second critical micelle concentration at a lower but unspecified concentration. ${ }^{35,36}$

\section{Light Scattering}

The Zimm plot shown in Figure $2 a$ for proteolipids in $2: 1(\mathrm{v} / \mathrm{v})$ chloroform-methanol exhibits considerable curvature that is characteristic for systems of molecular weight polydispersity. The steepness of the zeroangle line is indicative of the strong interaction between the solute and solvent. The magnitude of this interaction was determined by the differential refractometry experiments described in the section on results. The relatively small change in the weight-average aggregate weight and the large change in the radius of gyration upon changing solvents from $2: 1$ ( $\mathrm{v} / \mathrm{v})$ chloroform-methanol to $88.5 \%$ formic acid- $0.5 M$ sodium formate is good evidence for a change in the shape of the molecule. The observed aggregate weights are very similar to aggregate weights obtained for egg lecithin. ${ }^{37}$

\section{Osmotic Pressure}

The osmotic pressure curve obtained for solutions of proteolipid in $2: 1(\mathrm{v} / \mathrm{v})$ chloroform-methanol for the concentration range $0.09-0.285$ $\mathrm{g} / 100 \mathrm{ml}$ shows the presence of the critical micelle concentration at $0.2-0.25$ g/ $100 \mathrm{ml}$ (Fig. 5). Extrapolation of the linear portion of the curve below 
the critical micelle concentration is, therefore, a measure of the numberaverage aggregate weight $\left(7.2 \times 10^{4}\right)$ at the lower concentrations, whereas the light-scattering studies have given an indication of the aggregate weight, above a concentration of $0.2 \mathrm{~g} / 100 \mathrm{ml}$, of the order of $2.9 \times 10^{6}$. The steepness of the curve above the critical micelle concentration may be attributed to a large contribution of the second virial coefficient in the osmotic pressure equation. This is not unexpected, in view of the strong solute-solvent interaction that was shown to exist by light scattering.

\section{Viscosity}

The viscosity of lecithin solution in aqueous media is known to be Newtonian in behavior. ${ }^{38}$ Solutions of proteolipid in $2: 1(\mathrm{v} / \mathrm{v})$ chloroform-methanol and in $88.5 \%$ formic acid are also Newtonian. The viscosity curves of the dialyzed and undialyzed chloroform-methanol solutions are typical of materials displaying polyelectrolyte behavior. For the proteolipids, the effect may be due to a combination of the double layer charges on the micelle and of net charges on the protein. The effect is not large and appears to be completely supressed by $2.97 \times 10^{-3} \mathrm{M} \mathrm{NaCl}$. It is interesting to note that the effect becomes apparent in the region of the critical micelle concentration; occurring at ca. $0.21-0.24 \mathrm{~g} / 100 \mathrm{ml}$. The relatively large change in intrinsic viscosity of proteolipid solutions in $2: 1(\mathrm{v} / \mathrm{v})$ chloroform-methanol as compared to proteolipid solutions in $88.5 \%$ formic acid is interpreted as indicating a change in the shape of the micelle. For an unhydrated or unsolvated sphere the intrinsic viscosity should approach $0.025 \mathrm{dl} / \mathrm{g}$. Clearly, the values of $[\eta]$ obtained in the present study are much higher, and in chloroform-methanol the value of $[\eta]$ is sufficiently in excess of the value of 0.025 that even the solvent binding cannot be a significant factor. In formic acid solvent the solvation may be largely responsible for the observed value of $[\eta]$. The Huggins constant ${ }^{19} K_{1}$ and the Jirgensons constant ${ }^{20} k$ can be used as an indication of the shape of the complex. Jirgensons has found that the constant $k$ is between 0.005 and 0.02 for globular macromolecules, and this correlates well with the interpretation of the data obtained for proteolipids in $88.5 \%$ formic acid. The higher values of $k$ obtained for solutions of proteolipid in $2: 1(\mathrm{v} / \mathrm{v})$ chloroform-methanol are indicative of a rodlike or ellipsoid shape for the complex.

\section{Optical Rotatory Dispersion}

The opitcal rotatory dispersion studies of the proteolipids, in the solvents listed in Table III, are not amenable to unambiguous quantitative interpretation. Assignments of helical content to the protein moiety have been based on the Moffitt equation with the reservation that the numbers obtained must be considered in the light of possible contributions from the lipid component or from any asymmetry present in the aggregate itself. These studies may be interpreted as demonstrating structural or conformational changes of the proteolipid with change in solvent as reflected in the 
$b_{0}$ parameter. The optical rotatory dispersion of the proteolipid apoprotein shows the typical anomolous dispersion associated with a mixture of $\alpha$-helix and $\beta$ structure. It is estimated that the content of $\alpha$-helix for this material is low, $0-10 \%$.

\section{X-Ray}

The x-ray powder and film diagrams were devoid of any significant structure information. The observed reflection at $4.5 \AA$ normally present in lipid systems indicates the lack of order or crystallinity in the hydrocarbon side chains of the phospholipid. No reflections that could be attributed to the protein moiety were found, even with small-angle techniques.

\section{Lipids, Colloids, and Proteolipids}

The question of whether proteolipids exist per se in vivo or are artifacts created by the extraction process cannot be answered at this time. There is indirect evidence that can be interpreted in favor of their existence in myelin..$^{39,40}$ These workers have claimed that the structure of the myelin sheath was altered by changing its $\mathrm{pH}$ and $\mathrm{Ca}^{++}$to $\mathrm{Na}^{+}$ratio. These changes were interpreted as indicating changes similar to the changes exhibited by classical "oil-in-water" and "water-in-oil" emulsions. Also, some forty years ago it was shown that the hydration of myelin exhibited features similar to those characterizing the hydration of soaps. ${ }^{41}$

The structure of a brain phospholipid mixture has been studied as a function of temperature and water content and it was found that this material existed in either a lamellar or hexagonal micellar structure. ${ }^{42}$

The ability of lecithin to serve as an emulsifying or sol-promoting agent in aqueous and nonaqueous media is a well known phenomenon, and the colloidal properties of lecithin have also been extensively studied. ${ }^{43-46}$ Many of the characteristics of lecithin systems appear to be grossly similar to the characteristics of proteolipids.

The rather unique solvent system requirements of the brain proteolipids, as contrasted to pure lecithin systems, may be an indication that electrical repulsion is a less important factor in proteolipid micelle formation than is

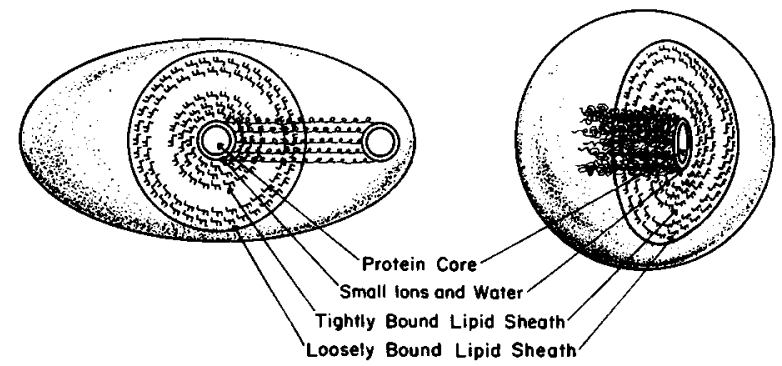

Structure I
Structure III

Figure 8.

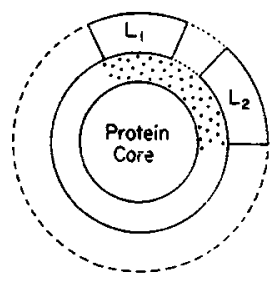

Structure II 
the organization of the solvent structure. A similar situation has been postulated to exist for micelle formation by long chain fatty acids in concentrated sulfuric acid. ${ }^{47}$

The data presently available on proteolipids and on phospholipids suggests that the structure of bovine white matter proteolipids in $2: 1(\mathrm{v} / \mathrm{v})$ chloroform-methanol above the critical micelle concentration might be better depicted as shown in structure I than as has been suggested by Folch in structure II. The structure of proteolipids in $88.5 \%$ formic acid would be more akin to structure II, but modified as shown in structure III. Structures I and III would appear to be in greater accord with the facts presently available.

The author acknowledges his thanks and appreciation to Professor Jordi Folch-Pi, Dr. Marjorie Lees, Professor J. L. Oncley, Professor Walter Stockmayer, and Professor Elkan Blout for their help, encouragement and hospitality during various stages of this investigation.

Portions of this work were carried out at the Research Laboratories, MeLean Hospital, Belmont, Mass., and the Department of Biological Chemistry, Harvard Medical School, Boston, Mass.

Supported by grants from the National Institutes of Health of the United States Public Health Service, NB-05306, GPD 12,706, and NB-00130.

A preliminary report of portions of this work has appeared in Federation Proceedings, 25, 736 (1966).

\section{References}

1. J. Folch and M. Lees, J. Biol. Chem., 191, 807 (1951).

2. C. Chatagnon, M. Mortreuil, J. P. Zalta, and P. Chantagnon, Bull. Soc. Chim. Biol., 35, 419 (1953).

3. Y. Kimura, Y. Taketomi, and T. Taketomi, Japan. J. Exptl. Med., 30, 361 (1960).

4. F. Wolfgram and A. Rose, J. Neurochem., 8, 161 (1961).

5. F. Wolfgram and A. Rose, J. Neurochem., 9, 923 (1962).

6. L. A. Autilio and W. T. Norton, J. Neurochem., 10, 733 (1963).

7. L. A. Autilio and W. T. Norton, J. Neurochem., 11, 17 (1964).

8. W. T. Norton and L. A. Autilio, Ann. N.Y. Acad. Sci., 122, 77 (1965).

9. G. R. Webster and J. Folch, Biochim. Biophys. Acta, 49, 399 (1961).

10. M. Matsumoto, R. Matsumoto, and J. Folch-Pi, J. Neurochem., 11, 829 (1964).

11. D. Tenenbaum and J. Folch-Pi, Biochim. Biophys. Acta, 115, 141 (1966).

12. J. Folch, G. R. Webster, and M. Lees, Federation Proc., 18, 898 (1959).

13. J. Folch-Pi, in Brain Lipids and Lipoproteins, J. Folch-Pi and H. J. Bauer, Eds., Elsevier, New York, 1963, pp. 18-30.

14. P. Debye, J. Phys. Colloid Chem., 53, 1 (1949).

15. B. H. Zimm, J. Chem. Phys., 16, 1099 (1948).

16. B. E. Read, Trans. Faraday Soc., 56, 383 (1960).

17. P. R. Saunders, J. Polymer Sci., 57, 131 (1962).

18. P. R. Saunders, J. Polymer Sci., A, 2, 3755 (1964).

19. M. Huggins, J. Am. Chem. Soc., 64, 2716 (1942).

20. B. Jirgensons and E. C. Adams, Makromol. Chem., 24, 159 (1957).

21. W. Moffitt, J. Chem. Phys., 25, 467 (1956); Proc. Natl. Acad. Sci. U.S., 42, 736 (1956).

22. A. Rouhi, J. Blass, and J. Polonovski, Bull. Soc. Chim. Biol., 36, 1417 (1954).

23. R. W. Hendler, Biočhim. Biophys. Acta, 60, 90 (1962). 
24. M. L. Das, H. Hiratsuka, J. M. Machinist, and F. L. Crane, Biochim. Biophys. Acta, 60, 433 (1962).

25. M. L. Das, D. E. Myers, and F. L. Crane, Biochim. Biophys. Acta, 84, 618 (1964).

26. M. L. I)as and F. L. Crane, Biochemistry, 3, 696 (1964).

27. M. L. Das, E. D. Haak, and F. L. Crane, Biochemistry, 4, 859 (1965).

28. R. Cavanna and M. M. Rapport, J. Lipid Res., 8, 65 (1967).

29. M. Lees, J. Neurochem., 13, 1407 (1966).

30. L. P. Zill and E. A. Harmon, Biochim. Biophys. Acta, 53, 579 (1961).

31. J. J. Duffy, S. Katoh, and A. San Pietro, Biochim. Biophys. Acta, 121, 201 (1966).

32. M. Murakami, H. Sekine, and S. Funahashi, J. Biochim., 51, 431 (1962).

33. H. Shichi, Y. Sugimura, and S. Funahashi, Biochim. Biophys. Acta, 97, 492 (1965).

34. W. Prins and J. J. Hermans, Koninkl. Ned. Akad. Wetenschap. Proc., B59, 162 (1956).

35. P. L. Elworthy, J. Chem. Soc., 1959, 813.

36. P. H. Elworthy, J. Chem. Soc., 1959, 1951.

37. D. Attwood and L. Saunders, Biochim. Biophys. Acta, 98, 344 (1965).

38. L. Saunders, J. H. Perrin, and D. Gammack, J. Pharm. Pharmacol, 14, 567 (1962).

39. M. Wolman, Biochim. Biophys. Acta, 102, 261 (1965).

40. M. Wolman and H. Wiener, Biochim. Biophys. Acta, 102, 269 (1965).

41. G. Friedel, Compt. Rend., 185, 330 (1927).

42. V. Luzzatti and F. Husson, J. Cell. Biol., 12, 207 (1962).

43. H. G. Bungenberg DeJong, A. DeBakker, and 1). Andrisse, Koninkl. Ned. Akad. Wetenschap. Proc., B58, 238 (1955).

44. H. G. Bungenberg DeJong, A. DeBakker, and D. Andrisse, Koninkl. Ned. Akad. Wetenschap. Proc., B58, 251 (1955).

45. H. G. Bungenberg DeJong, A. JeBakker, and 1). Andrisse, Koninkl. Ned. Akad. Wetenschap. Proc., B58, 257 (1955).

46. H. G. Bungenberg DeJong and A. DeBakker. Koninkl. Ned. Akad. Wetenschap. Proc., B59, 124, 136, 149 (1956).

47. J. Steigman and N. Shane, J. Phys. Chem., 69, 968 (1965).

Received January 2, 1968 